\title{
THE EFFECT OF PARAMETERS AND GEOMETRY CUTTING EDGE AFTER TURNING OF THE DUPLEX CAST STEEL ON THE MAXIMUM TOOL FLANK WEAR
}

\author{
Tomasz Cyryl Dyl \\ Gdynia Maritime University \\ Faculty of Marine Engineering \\ Department of Marine Maintenance \\ Morska Street 81-87, 81-225 Gdynia, Paland \\ tel.: +48585586323, fax: +48585586399 \\ e-mail:t.dyl@wm.umg.edu.pl
}

\begin{abstract}
It is important to shape the required properties of the surface layer in the technological process. This issue is an important problem due to the ability of the kinematic pair elements to the required reliable operation of machine parts. The latest generation devices work with increasing operational loads. This forces the search forever-newer construction materials or innovative manufacturing engineering technologies that would ensure high reliability and durability of machine components. For mechanical engineering, continue to be used on steel structures of machine parts. In the petrochemical and shipbuilding industry, stainless steels are very poplars. Those materials are used in the constructions of seawater and acid installations. Currently, a newer material with more favourable properties is two-phase stainless steel. This is the so-called duplex steel. It can be applied to pump shafts in acid or seawater solutions. Duplex cast steel is a difficult-to-cut material. It is important to determine the effect of cutting parameters on the surface quality of the shafts and wear of cutting edge. Traditional methods of finishing surface treatment of shafts are machining (turning, grinding, superfinishing). Considering the possibilities of equipping a marine power plant workshop, it would be best to use machining by turning.

The paper specifies the relationship between the wear of the cutting edge and the geometrical structure of the machined surface as well as the type of tool material used and the shape of the cutting inserts.
\end{abstract}

Keywords: turning, surface roughness, duplex cast steel, cutting edge, flank wear

\section{Introduction to the topic}

The surface machining is carried out to improve the quality of the surface layer of the materials. Thus is a need to shape the desired properties of the surface layer by selecting appropriate technological processes [2-13, 18]. It is significant that in special applications of corrosion resistant steel, low surface roughness is obtained. Duplex stainless steel is becoming more widely used for example in the petrochemical industry or shipbuilding. Duplex stainless steel is a material classified as difficult-to-cut $[1,7-11,16]$. It is therefore important to investigate the impact of machining parameters on the durability and wear of a cutting edge $[15,19]$. It is important to determine the effect of processing on tool life while maintaining a high surface quality shafts. In the paper was determined the influence of variables machining on the flank wear. Surface machining was carry out with carbide tipped inserts.

Figure 1 presents a laboratory stand for longitudinal rolling of external cylindrical surfaces.

One of the finishing treatments used to shape the surface layer of the product is machining by turning. It is a treatment that involves the shaping of technological properties using a turning tool with the right geometry cutting edge. Separation of the machined layer from the workpiece takes place via a monometallic, bimetallic tool or with interchangeable cutting inserts, moving at the cutting speed relative to the machined surface. The essential feature of turning is the proper association of the rotational movement of the workpiece and the linear movement of the tool. 


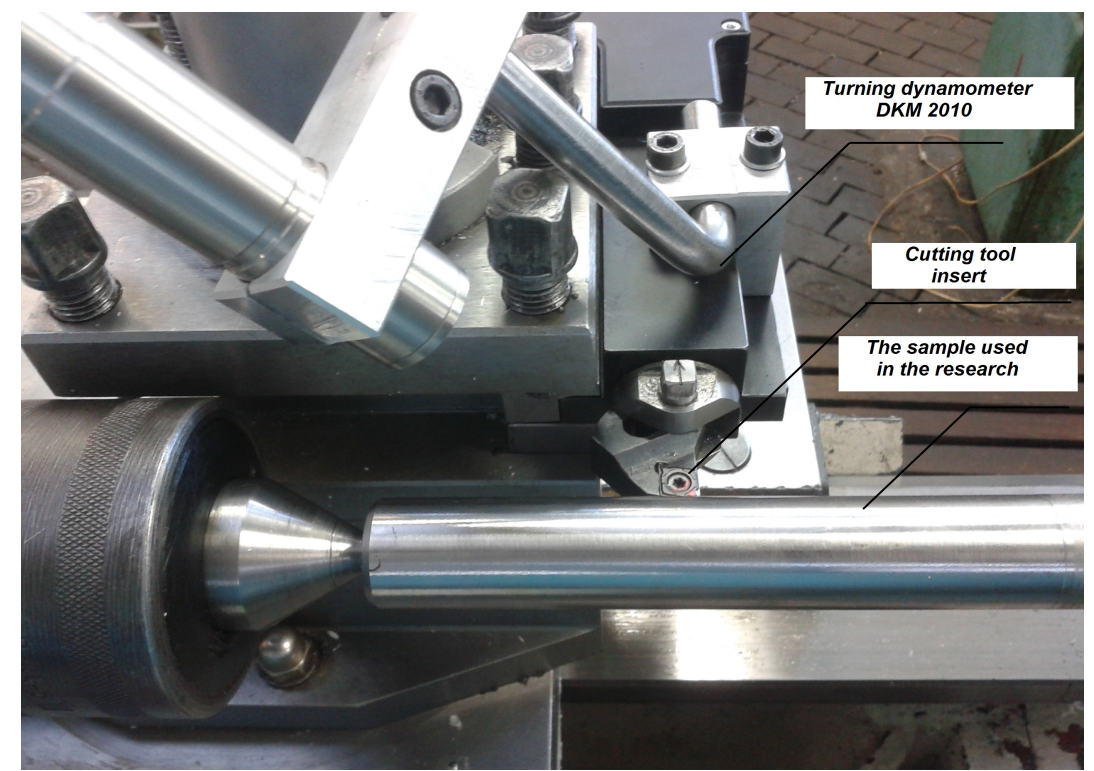

Fig. 1. The turning of outside cylinder-shaped surfaces from tool insert with dynamometer DKM2010

\section{Research realization methods}

The samples made of duplex cast steel in the shape of external cylindrical surfaces were prepared by medium longitudinal turning on a universal lathe CDS 500x1000 located in the Laboratory of Production Engineering of the Gdynia Maritime University, Faculty of Marine Engineering, Department of Marine Maintenance. Cutting parameters were selected on the basis of literature $[8-12,17,21]$ and own research. The following cutting parameters were used for machining: feed rate from $0.1 \mathrm{~mm} / \mathrm{rev}$ to $0.2 \mathrm{~mm} / \mathrm{rev}$, depth of cut $0.5 \mathrm{~mm}$, rotational speed from $600 \mathrm{rpm}$ to $1220 \mathrm{rpm}$, cutting speed from $50 \mathrm{~m} / \mathrm{min}$ to $100 \mathrm{~m} / \mathrm{min}$. Turning cooling was not used, treatment was made dry.

The criterion of the smallest roughness and the highest wear was proposed. The criterion for selecting the right cutting inserts geometries for finishing was the arithmetical mean deviation of the ordinates of the surface roughness profile, which should be within the range from $0.16 \mu \mathrm{m}$ to $1.63 \mu \mathrm{m}$ and the second criterion is of the maximum tool flank wear $0.3 \mathrm{~mm}$. The types of inserts shape CC09T3 were proposed for machining where all are made of sintered carbides of the 2025 grade with a CVD Ti(C,N)/ $\mathrm{Al}_{2} \mathrm{O}_{3} / \mathrm{TiN}$ [21] (Tab. 1). Turning tools are characterized by the following properties: cutting edge angle $90^{\circ}$, tool-included angle $80^{\circ}$, rake angle from $6^{\circ}$ to $7^{\circ}$, flank angle $7^{\circ}$, nose radius $0.397 \mathrm{~mm}$ and $0.794 \mathrm{~mm}$.

During machining of duplex cast stainless steel in the type GX2CrNiMoCuN25-6-3-3 low durability of the tool may occur, therefore a constant value of the cutting path was determined for the needs of the tests. The length cutting, which are chosen for recommended cutting, thus allowing for a reliable process. Length of spiral cutting is a constant $(L c=10.5 \mathrm{~m})$ and applied to the insert, geometry, and grade, depth of cut and material that shall be subject machined.

Tab. 1. The types of inserts shape CC09T3 used for turning of cylinder-shaped samples with cast stainless steel

\begin{tabular}{|c|c|c|c|c|}
\hline Insert Shape and Type & Insert Grade & $\begin{array}{c}\text { Nose Radius } \\
\text { [mm] }\end{array}$ & $\begin{array}{c}\text { Flank Angle } \\
{\left[^{0}\right]}\end{array}$ & $\begin{array}{c}\text { Rake Angle } \\
{\left[{ }^{\circ}\right]}\end{array}$ \\
\hline CCMT 09T308-MM & \multirow{3}{*}{2025} & \multirow{2}{*}{0.794} & \multirow{3}{*}{7} & 7 \\
\hline CCMT 09T308-UM & & & & \multirow{2}{*}{6} \\
\hline CCMT 09T304-UM & & 0.397 & & \\
\hline
\end{tabular}


To determine the length of spiral cutting $(L c)$ can be used the formula:

$$
L c=(\pi d l) /(1000 f) \text {, }
$$

where:

$d$ - the diameter of the workpiece in the machined surface, $[\mathrm{mm}]$,

$l$ - length of the cutting surface, $[\mathrm{mm}]$,

$f$ - feed rate, $[\mathrm{mm} / \mathrm{rev}]$.

The surface of duplex cast steel was measured using a profilometer HT1000. Measurements were performed to the principles contained in standards with for the elementary section the lengths of $4.8 \mathrm{~mm}$ and $0.8 \mathrm{~mm}$. An amount of parameters of surface roughness after machining were determined, among other things, parameters were defined associated with the material ratio curve. Force were measured with tool dynamometer DKM2010 on the cutting tools is measured up to $2000 \mathrm{~N}$. Observation and measurement of the cutting inserts wear after turning of samples was carried out using digital industrial microscope SmartZoom 5.

Experimental study was made for samples from duplex cast stainless steel type GX2CrNiMoCuN25-6-3-3, which chemical composition is presented in Tab. 2, was analysed using an optical emission spectrometry by Solaris CCD Plus. The two-phase cast stainless steel is submit of many material and processing study, it is characterized with higher tensile strength and better resistance to stress corrosion in comparison to stainless steel [1, 7-11, 14-16, 20].

Tab. 2. The chemical composition for samples from duplex cast stainless steel and mechanical properties [14, 20]

\begin{tabular}{|c|c|c|c|c|c|c|c|c|c|}
\hline $\begin{array}{c}\mathbf{C} \\
{[\%]}\end{array}$ & $\begin{array}{c}\mathbf{C r} \\
{[\%]}\end{array}$ & $\begin{array}{c}\mathbf{N i} \\
{[\%]}\end{array}$ & $\begin{array}{c}\mathbf{M} 0 \\
{[\%]}\end{array}$ & $\begin{array}{c}\mathbf{C u} \\
{[\% \mathbf{\%}]}\end{array}$ & $\begin{array}{c}\mathbf{N} \\
{[\% \mathbf{\%}]}\end{array}$ & $\begin{array}{c}\mathbf{M n} \\
{[\% \mathbf{\%}]}\end{array}$ & $\begin{array}{c}\mathbf{S i} \\
{[\% \mathbf{\%}]}\end{array}$ & $\begin{array}{c}\mathbf{S} \\
{[\%]}\end{array}$ & $\begin{array}{c}\mathbf{P} \\
{[\% \mathbf{\%}]}\end{array}$ \\
\hline 0.03 & 24.5 & 6.1 & 3.2 & 2.9 & 0.25 & 0.5 & 0.9 & 0.020 & 0.008 \\
\hline $\begin{array}{c}\mathbf{R}_{\mathbf{p} 0.2} \\
\text { standard } \\
{[\mathbf{M P a}]}\end{array}$ & $\begin{array}{c}\mathbf{R}_{\mathbf{p} 0.2} \\
{[\mathbf{M P a}]}\end{array}$ & $\begin{array}{c}\mathbf{R}_{\mathbf{m}} \\
\text { standard } \\
{[\mathbf{M P a}]}\end{array}$ & $\begin{array}{c}\mathbf{R}_{\mathbf{m}} \\
{[\mathbf{M P a}]}\end{array}$ & $\begin{array}{c}\mathbf{\rho} \\
{\left[\mathbf{k g} / \mathbf{m}^{3}\right]}\end{array}$ & $\begin{array}{c}\mathbf{E} \\
{[\mathbf{G P a}]}\end{array}$ & $\begin{array}{c}\mathbf{A}_{\mathbf{5}} \\
{[\mathbf{\%}]}\end{array}$ & $\mathbf{H V 0 . 1}$ & $\begin{array}{c}\boldsymbol{\lambda} \\
{[\mathbf{J} / \mathbf{m} \cdot \mathbf{s} \cdot \mathbf{K}]}\end{array}$ & $\begin{array}{c}\mathbf{c}_{\mathbf{w}} \\
{[\mathbf{J} / \mathbf{k g} \cdot \mathbf{K}]}\end{array}$ \\
\hline 480 & 520 & 650 & 680 & 7850 & 200 & 20 & 392 & 15 & 500 \\
\hline
\end{tabular}

\section{Results of experimental study}

In the Laboratory of Engineering Production in Department of Marine Maintenance were conducted experimental studies involving finishing of the outer cylindrical surface of the duplex cast steel.

After research were determined technological parameters of the longitudinal turning of cylindrical samples that the roughness and tool wear is affected.

In Tab. 3 was shown exemplary results of measurements of surface roughness and wear of cutting edge after turning, for different values of cutting speed, feed rate, and the constant cutting depth. Parameter $\mathrm{Ra}$ is the arithmetical mean deviation of the roughness profile of the surface and parameter $\mathrm{Rz}$ is maximum height of profile average value of the five measurement. These parameters were measured according to the ISO 4287 standard. The surface roughness reduction ratio $(\mathrm{KRa})$ is determined quotient the arithmetical mean deviation before to after machining [3].

Taking into account the use of different feed values for the remaining constant parameters cutting. It can be seen that for a smaller feed rate of $f=0.1 \mathrm{~mm} / \mathrm{rev}$, with a constant cutting speed $v_{c}=70 \mathrm{~m} / \mathrm{min}$ and depth of cut $a_{p}=0.5 \mathrm{~mm}$, using a CCMT 09T304-UM, even lower values of roughness parameters are obtained than for the other machined surfaces using feed rate $f=$ $0.2 \mathrm{~mm} / \mathrm{rev}$. The surface roughness reduction ratio was equal to $\mathrm{KRa}=3.21$, which is the highest value the presented scope of research (Fig. 2). For different geometries and types of cutting inserts and for values of the machining parameters: cutting speed $v_{c}=70 \mathrm{~m} / \mathrm{min}$, feed rate $f=0.2 \mathrm{~mm} / \mathrm{rev}$, depth of cut $a_{p}=0.5 \mathrm{~mm}$, was determined, that the machined surface of steel samples after turning 
with insert CCMT 09T308-UM obtains low values of roughness parameters. The arithmetical mean deviation and the maximum height of profile and the surface roughness reduction ratio after turned samples by the program included in Tab. 3 can be seen in Fig. 2.

Tab. 3. The example indicators of wear of a cutting edge and of measurements of the parameter of surface roughness for inserts used for turning cylindrical samples with cast steel duplex

\begin{tabular}{|c|c|c|c|c|c|c|c|c|}
\hline No of Samples & Insert Shape and Type & $\begin{array}{c}f \\
{[m m / r e v]}\end{array}$ & $\begin{array}{c}v_{c} \\
{[\mathrm{~m} / \mathrm{min}]}\end{array}$ & $\begin{array}{c}R z \\
{[\mu m]}\end{array}$ & $\begin{array}{c}R a \\
{[\mu m]}\end{array}$ & $\begin{array}{c}\text { KRa } \\
\text { [-] }\end{array}$ & $\begin{array}{c}V B \\
{[m m]}\end{array}$ & $\begin{array}{c}K B \\
{[m m]}\end{array}$ \\
\hline 09T308-MM-100 & \multirow{3}{*}{ ССМТ 09T308-ММ } & 0.2 & 100 & 9.19 & 1.93 & 1.71 & 0.24 & 0.12 \\
\hline 09T308-MM-70 & & 0.2 & 70 & 8.51 & 1.64 & 2.01 & 0.20 & 0.09 \\
\hline 09T308-MM-50 & & 0.2 & 50 & 11.97 & 2.31 & 1.43 & 0.29 & 0.14 \\
\hline 09T308-UM-100 & \multirow{3}{*}{ CCMT 09T308-UM } & 0.2 & 100 & 7.55 & 1.53 & 2.16 & 0.11 & 0.05 \\
\hline 09T308-UM-70 & & 0.2 & 70 & 7.44 & 1.55 & 2.13 & 0.09 & 0.05 \\
\hline 09T308-UM-50 & & 0.2 & 50 & 8.15 & 1.63 & 2.02 & 0.14 & 0.07 \\
\hline 09T304-UM-70-2 & \multirow{2}{*}{ CCMT 09T304-UM } & 0.2 & 70 & 13.85 & 3.03 & 1.09 & 0.06 & $\mathbf{0 . 0 3}$ \\
\hline 09T304-UM-70-1 & & 0.1 & 70 & 5.28 & 1.03 & 3.21 & 0.03 & 0.02 \\
\hline
\end{tabular}

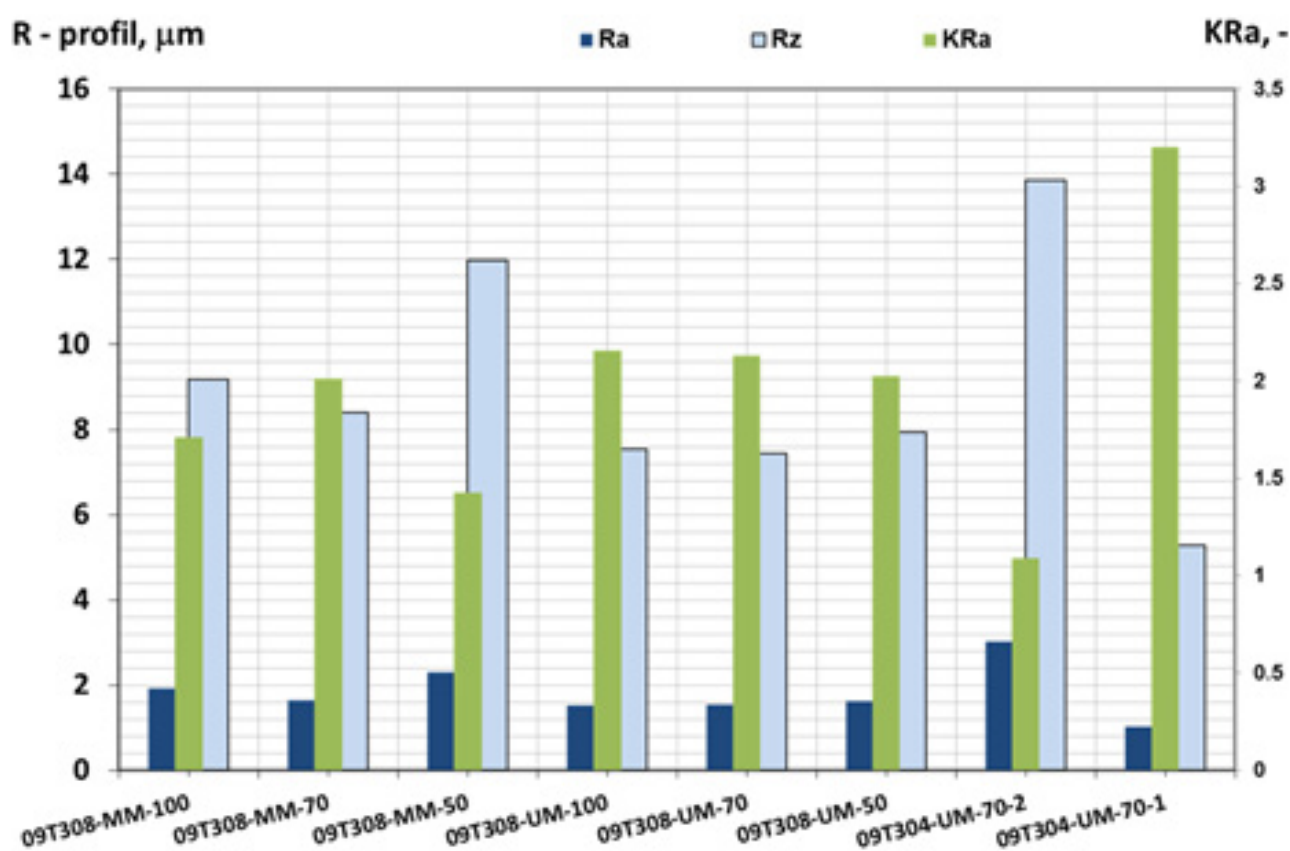

\section{No of samples}

Fig.2. The arithmetical mean deviation (Ra) and the maximum height of profile (Rz) and the surface roughness reduction ratio (KRa) after turned samples

The Fig. 3 shows the wear of a cutting edge: flank wear (VB, $\mathrm{mm})$ and crater wear $(\mathrm{KB}, \mathrm{mm})$ for different inserts according to the research program in Tab. 3.

All values shown in Fig. 3 they are within the given limit. It can therefore be concluded that the tools used for testing meet the wear criterion.

Figure 4 shown the cutting inserts used to process a duplex cast steel with visible wear, wipe, abrasive, wear land and build-up effects. 


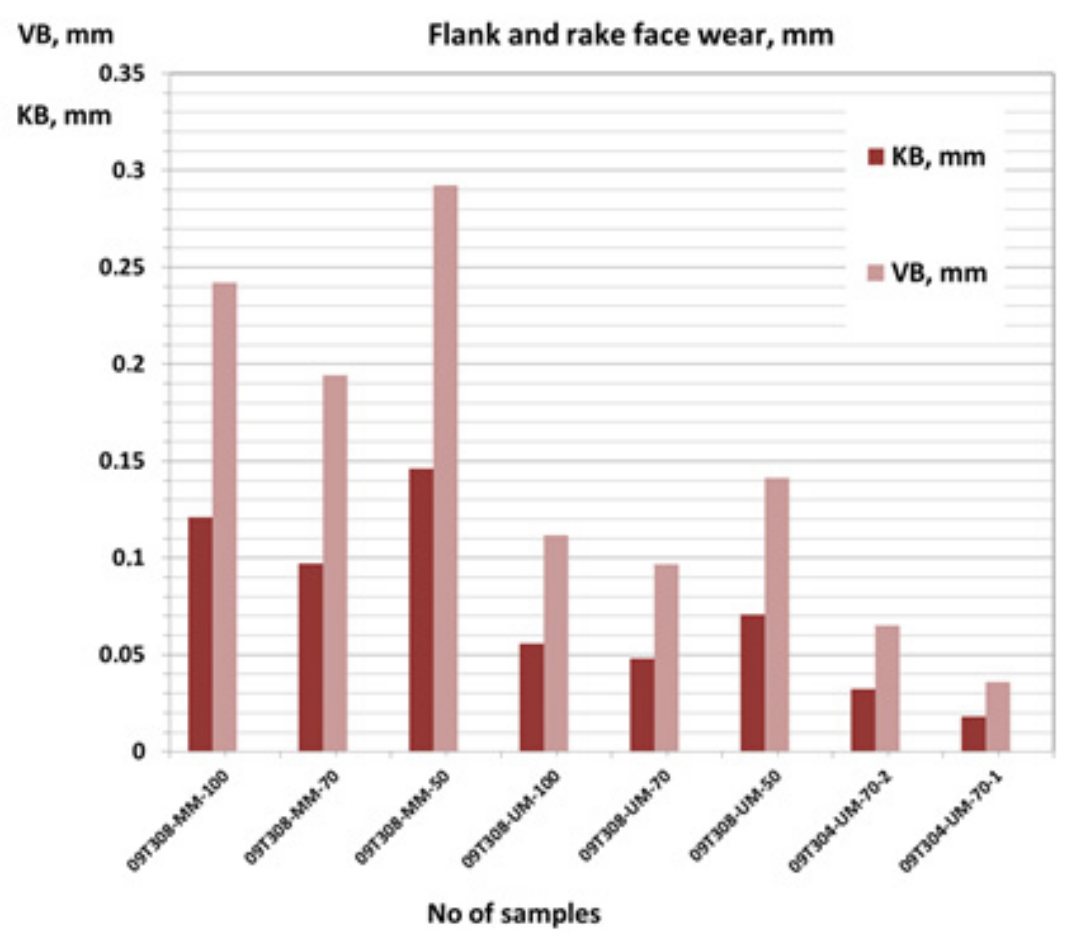

Fig. 3. The wear of a cutting edge: flank wear $(\mathrm{VB}, \mathrm{mm})$ and crater wear $(\mathrm{KB}, \mathrm{mm})$ for different inserts

a)

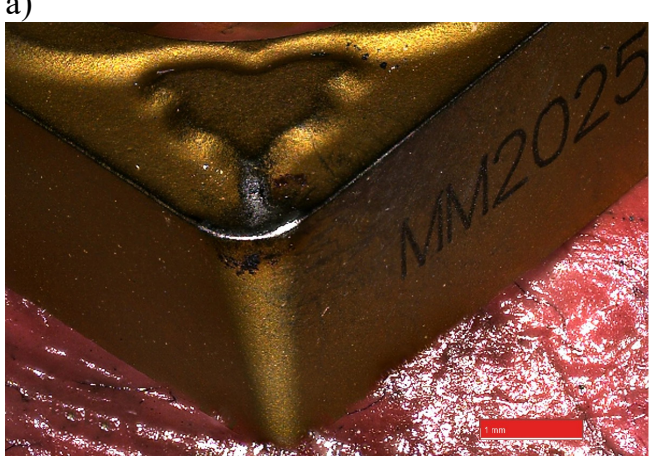

b)

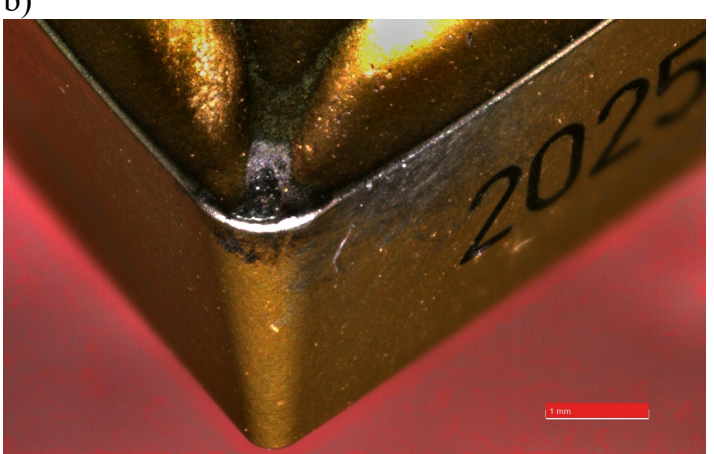

c)

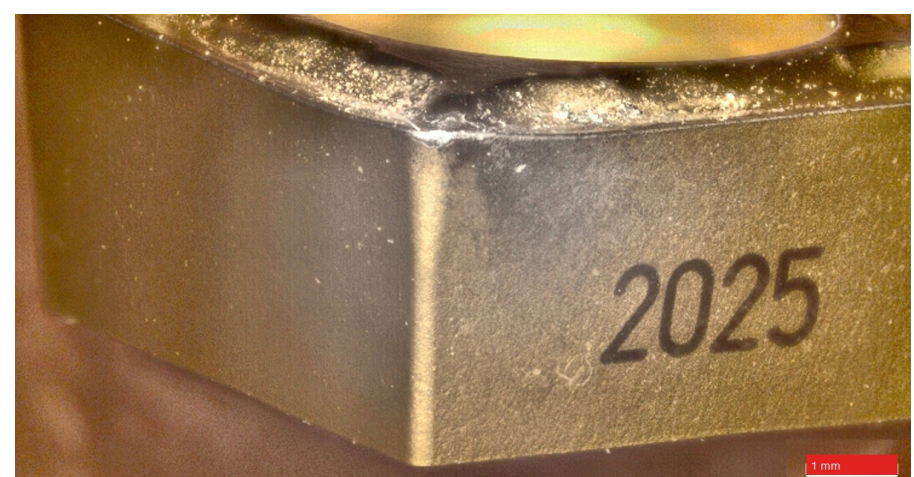

Fig. 4. The wear of the cutting inserts: a) CCMT 09T308-MM; b) CCMT 09T308-UM; c) CCMT 09T304-UM

After the analysed experimental study can be defined that to achieve a reduction in surface roughness after the longitudinal turning finishing of the samples of the duplex cast stainless steel, should be use with a constant cutting speed $v_{c}=70 \mathrm{~m} / \mathrm{min}$ and depth of cut $a_{p}=0.5 \mathrm{~mm}$ for different feed $f=0.2 \mathrm{~mm} / \mathrm{rev}$, for the cutting insert CCMT 09T308-UM 2025 or feed $f=0.1$ $\mathrm{mm} / \mathrm{rev}$ for cutting insert CCMT 09T304-UM 2025. For example cutting forces for turning the main cutting force assumes the highest values of $390 \mathrm{~N}$, while the feed force has the smallest value 
of $100 \mathrm{~N}$, and the resisting force assumes the values $250 \mathrm{~N}$ of the cutting insert CCMT 09T308UM 2025, for feed rate $f=0.2 \mathrm{~mm} / \mathrm{rev}$ and cutting speed $v_{c}=70 \mathrm{~m} / \mathrm{min}$ and depth of cut $a_{p}=0.5 \mathrm{~mm}$ was determined.

Afterwards the experimental analysis carried out; with the given processing parameters of the finishing of shaft with duplex cast stainless steel. It was determined that the insert shape and type and grade of the turning tools as well as the technological parameters of the machining have an impact on the reduction of roughness and the correct distribution of cutting forces and wear of cutting edge.

\section{Summary}

The manufactured products used in components of machines it is essential them to be assured required technological quality of the surface layer. The paper were presented the influence of the geometry of the cutting edge and machining parameters of duplex cast stainless steel after turning on the surface roughness reduction ratio and wear of the cutting inserts.

The turning of external cylindrical surfaces of duplex cast stainless steel in the GX2CrNiMoCuN25-6-3-3 grade was carried out by inserts shape CC09T3 of the grade 2025 with applied coating by CVD method.

After the experimental research it was determined that there was reducing in the surface roughness using the appropriate cutting edge geometry and for the given cutting parameters.

For precision machining the duplex cast stainless steel should be carried out using the cutting insert CCMT 09T304-UM 2025 for the nose radius $r_{\varepsilon}=0.397 \mathrm{~mm}$ with cutting parameters: feed rate $f=0.1 \mathrm{~mm} / \mathrm{rev}$, cutting speed $v_{c}=70 \mathrm{~m} / \mathrm{min}$, depth of cut $a_{p}=0.5 \mathrm{~mm}$, then it was occurred lowest values the wear of a cutting edge: flank wear $\mathrm{VB}=0.03 \mathrm{~mm}$ and crater wear $\mathrm{KB}=0.02 \mathrm{~mm}$. It would also be possible to use CCMT 09T308-UM 2025 cutting insert with a value of the nose radius $\mathrm{r}_{\varepsilon}=0.794 \mathrm{~mm}$, then should be used feed rate $f=0.2 \mathrm{~mm} / \mathrm{rev}$ and cutting speed $v_{c}=70$ $\mathrm{m} / \mathrm{min}$ and depth of cut $a_{p}=0.5 \mathrm{~mm}$, and flank wear $\mathrm{VB}=0.09 \mathrm{~mm}$ and crater wear $\mathrm{KB}=0.05 \mathrm{~mm}$.

All cutting inserts in use meet the wear criterion of the maximum tool flank wear $\mathrm{VB}=0.3 \mathrm{~mm}$. However, only two inserts (CCMT 09T304-UM 2025 and CCMT 09T308-UM 2025) meet the quality criterion, where Ra parameter is less than the value of $1.63 \mu \mathrm{m}$. [1]

\section{References}

[1] American Standard ASME B46.1-1995 for Surface Texture and the German Standard DIN 4776 for the Rk group of parameters, 1995'

[2] Armas, I. A., Moreuil, S. D., Duplex stainless steels, UK \& USA: ISTE Ltd. John Wiley \& Sons Inc., 2009.

[3] Burakowski, T., Wierzchoń, T., Surface Engineering of Metals: Principles, Equipment, Technologies, Materials Science \& Technology, CRC Press LLC, London, New York, Washington D.C. 1999.

[4] Dyl, T., Numerical and experimental analysis of burnishing process using the theory of elasticity and plasticity, Monographs - Gdynia Maritime University, Gdynia 2014.

[5] Dyl, T., Starosta, R., The effect of geometry and grades inserts turned alloy coatings, Inżynieria Materiałowa, Materials Engineering, 4, 182, pp. 395-398, 2011.

[6] Dyl, T., Starosta, R., Determination of the impact of the geometry and type of material inserts on topography turned composite coatings, Inżynieria Materiałowa, Materials Engineering, 6, 190, pp. 701-704, 2012.

[7] Dyl, T., Starosta, R., Improving the quality of technological surfaces of machines of composite coatings, Journal of KONES, Vol. 21, No. 1, pp. 75-82, 2014.

Manuscript received 25 March 2019; approved for printing 25 June 2019 
[8] Dyl, T., Rydz, D., Stradomski G., Burnishing cast stainless steels duplex in the aspect of increasing hardness and surface roughness reduction, Scientific Journal of Gdynia Maritime University, 100, pp. 76-86, 2017.

[9] Koyee, R. D., Heisel, U., Eisseler, R., Schmauder, S., Modeling and optimization of turning duplex stainless steels, Journal of Manufacturing Processes, 16, pp. 451-467, 2014.

[10] Królczyk, G., Legutko, S., Gajek, M., Predicting the surface roughness in the dry machining of duplex stainless steel (DSS), Metalurgija, 52, 2, pp. 259-262, 2013.

[11] Królczyk, G., Niesłony, P., Legutko, S., Determination of tool life and research wear during duplex stainless steel turning, Archives of Civil and Mechanical Engineering, Vol. 15, No. 2, pp. 347-354, 2015.

[12] Królczyk, G., Niesłony, P., Legutko, S., Hloch, S., Samardzic, I., Investigation of selected surface integrity features of duplex stainless steel (DSS) after turning, Metalurgija, 54, 1, pp. 91-94, 2015.

[13] Labuda, W., The influence of changing of cutting parameters on temperature and cutting forces during turning process of stainless steel with CCET09T302R-MF insert, Journal of KONES, Vol. 24, No. 4, pp. 133-140, 2017.

[14] Legutko, S., Nosal, S., The evolution of technological and operational surface machine parts, PAN, Poznan 2004.

[15] Nowacki, J., Duplex steel and its weldability, WNT, Warszawa 2009.

[16] Paro, J., Hanninen, H., Kauppinen, V., Tool wear and machinability of HIPed P/M and conventional cast duplex stainless steels, Wear 249, pp. 279-284, 2001.

[17] Ran, Q., Li, J., Xu, Y., Xiao, X., Yu, H., Jiang, L., Novel Cu-bearing economic al 21Cr duplex stainless steels, Materials and Design, 46, pp. 758-765, 2013.

[18] Sandvik Coromant catalogues and handbooks, Turning tools, Sandviken 2017.

[19] Starosta, R., Dyl, T., Surface treatment, Gdynia Maritime University, Gdynia 2008.

[20] Starosta, R., Dyl, T., Finishing of flame sprayed Ni-Al coatings, estimate of CBN inserts wear, Tribologia, Teoria i Praktyka, 4, pp. 245-252, 2011.

[21] Stradomski, G., The impact of the morphology of the sigma phase on shape properties of steel and cast steel duplex, Czestochowa University of Technology, Czestochowa 2016.

[22] Tools for metal cutting, Turning tools, Turning inserts and grades for stainless steel, CoroTurn ${ }^{\circledR 107}$ grade:2025, Sandvik Coromant, http://www.sandvik.coromant.com/enus/products/pages/tools.aspx, 5.05.2019. 